Running Head: Anger Expression in Organizations

An Empirical Examination of the Dual Threshold Model of Anger Expression

\author{
Lisa T. Stickney* and Deanna Geddes \\ Department of Human Resource Management \\ Fox School of Business and Management
}

Temple University

1810 N. $13^{\text {th }}$ Street

Philadelphia, PA 19122

Tel: (215) 204-5249

Fax: (215) 204-8362

$\underline{\text { Lts@temple.edu }}$

geddes@temple.edu

* Ph.D. student 


\begin{abstract}
This exploratory study examines the suppression and expression of anger at work within the framework of Callister \& Geddes' (2004) Dual Threshold Model. Data for the study were collected from surveys reflecting a critical incident methodology. Findings support the hypotheses that organizational silence leads to negative workplace outcomes, and expressed anger leads to positive workplace outcomes. There was partial support for the hypothesis that workplace displays of excessive anger negatively impact the offender and the situation that initially provoked the display. Also supported was the hypothesis that negative outcomes would increase when organizational members respond with sanctioning behavior toward the individual whose anger expression was viewed as excessive. Qualitative data were used to examine factors that encourage people to suppress or express their anger at work, as well as the types and frequency of supportive and sanctioning responses to anger displays by organizational observers.
\end{abstract}

Keywords: Anger Expression, Emotion, Supportive Climate 


\section{An Empirical Examination of the Dual Threshold Model of Anger Expression}

The view that organizations are emotional arenas (Fineman, 1993; 2000) is fast replacing the classical perspective that the workplace and those within it are fundamentally rationalproducing only reasoned discourse and interactions designed to prevent friction through neutrality and projected politeness. The "emancipation of emotions," emerging in part from a reduction in formalization within the workplace, is said to enhance our tolerance for more kinds of impulses and expressions among organizational members (Mastenbroek, 2000). This increased likelihood and legitimacy of emotional expression, however, brings a warning that while strict control or suppression of emotions at work is no longer sufficient or desirable, emotion management remains a necessary competency. Not surprisingly, the emotion perhaps most associated with this cautionary reminder is anger.

Anger is a protective emotion, a response to a perceived threat (Shunk, 2003). Those who experience anger are said to feel insulted or demeaned by individual or organizational action, e.g., inappropriate or unfair actions by another, and perceived indifference, inaction, or disrespect regarding legitimate requests. Consequently, when organizational members choose to express anger, they attempt to preserve, retrieve, or in some cases, enhance their personal or social identity and dignity (Lazarus, 1999). Expressed anger also serves as a signal to others of a problematic situation that may impact fellow employees and the organization as a whole (Callister \& Geddes, 2004). Thus, expressing anger has not only an individual preservation function, but an organizational preservation function as well. As Fineman (2003) reminds, "Organizations change or stagnate because of the emotions that energize or freeze people" (p. 1). 
Although anger expression appears to serve many prosocial functions, i.e., restoring offended individuals' dignity and highlighting areas of necessary organizational change, workplace anger is more often characterized with antisocial functions, such as producing unfavorable and destructive outcomes. For instance, anger is often associated with incivility, aggression and violence, as offended organizational members try to "even the score" with offenders by attempting to harm them or the organization itself (Andersson, 1999; Geddes \& Baron, 1997; Neuman \& Baron, 1998). Thus, expressing anger in the workplace appears to produce both positive and negative outcomes, though it is less clear when one or the other will result. The exploratory research reported here examines this issue to better understand when expressed anger is more likely to lead to favorable and unfavorable consequences for organizations and its members.

The recently proposed Dual Threshold Model of anger expression (Callister \& Geddes, 2004) provides the conceptual framework from which we explore this question. The following section briefly reviews the model and introduces hypotheses and research questions that allow us to empirically test some of its key propositions.

\section{THE DUAL THRESHOLD MODEL OF ANGER EXPRESSION}

The Dual Threshold Model of expressing anger in organizations proposes that two thresholds exist when individuals experience anger in the workplace (see Figure 1). The "Expression Threshold" is crossed when an organizational member decides to speak up and express felt anger, rather than silence it. The second boundary, the "Impropriety Threshold," is crossed when organizational members go too far while expressing their anger, such that observers find their actions socially and/or culturally inappropriate. Callister and Geddes (2004) argue that negative consequences will likely result from one of two situations: When 
organizational members choose to remain silent, rather than express their anger (i.e., they fail to cross the Expression Threshold), and when organizational members cross both thresholds, termed the "double cross," expressing anger in a socially or culturally unacceptable manner. In contrast, positive consequences result when expressed anger stays in the space between the Expression and Impropriety Thresholds. This space is variable and can be reduced or expanded as a result of organizational norms associated with supporting emotional displays (expanding the space) or suppressing emotional displays (reducing the space).

\section{The Expression Threshold}

Callister and Geddes (2004) propose that there are two types of "silent anger," i.e., felt anger that does not cross the Expression Threshold. The first, and most obvious is when offended organizational members choose to hide, suppress or transform their anger. Individuals may choose not to speak up for many reasons_-indifference and cynicism, fear of repercussions, job requirements, personality traits, etc. (Andersson, 1996; Morrison \& Milliken, 2000). The second type of silent anger is when organizational members communicate their anger to individuals unrelated to the initially problematic situation and/or not in a position to help change it. For instance, the model suggests that individuals remain "organizationally silent" when they express their anger to family and friends outside the organization. Callister and Geddes (2004) also argue that complaining or gossiping with coworkers is another form of silent anger, since no attempt is made to express anger to those able to address the situation.

Individuals who silence their anger are found to experience feelings of humiliation and resentment (Perlow \& Williams, 2003), frustration and tension (Callister, Gray, Schweitzer, Gibson, \& Tan, 2003), emotional exhaustion, burnout and stress (Morris \& Feldman, 1996), as well as reduced productivity, motivation and creativity (Perlow \& Williams, 2003). In addition to 
the substantial possibilities of negative consequences for individuals, organizations also suffer negative consequences when such persons choose not to cross the Expression Threshold. Key among these problems is that necessary change efforts and decision making may be thwarted with this reduced form of employee feedback (Waldron \& Krone, 1991). Company reputations may also be damaged as individuals express anger to those outside the organization (Gundlach, Douglas, \& Martinko, 2003), and negative emotional contagion, with corresponding reduced loyalty, morale and productivity, may result when employees express anger to company members who are not in a position to respond to the initial problematic situation (Barsade, 2002; Kelly \& Barsade, 2001).

Thus, when individuals choose to remain organizationally silent and not express their anger to influential parties such as their manager or individuals involved in the problematic situation, the Dual Threshold Model proposes that significant negative consequences result. To test this proposal, we offer the following hypothesis:

Hypothesis 1: When angry organizational members refrain from crossing the Expression Threshold and remain silent, negative outcomes increase.

We also pursue the following research questions:

Research Question 1: What makes individuals less likely to speak up at work when angry?

Research Question 2: What makes individuals more likely to speak up at work when angry?

The Space Between the Thresholds

The Dual Threshold Model suggests that the space between the Expression and Impropriety Thresholds is where organizational anger is expressed in such a way that does not 
cross socially and/or culturally constructed boundaries of propriety. The positioning of the Impropriety Threshold determines the size of this space, such that if organizational cultures are more encouraging or supportive of expressing strong emotions like anger, this threshold is pushed away from the Expression Threshold, "opening up" a space for sanction-free expression.

Once felt anger crosses into the space beyond the Expression Threshold, organizational members are responsible for managing their emotional display so that it does not cross the Impropriety Threshold. Often this stems from a commitment to be respectful of colleagues, referred to as "intersubjective limitations" in Bounded Emotionality Theory (Martin, Knopoff, \& Beckman, 1998; Meyerson, 1998; Putnam \& Mumby, 1993). An ability to express anger in a way deemed socially responsible reflects aspects of emotional intelligence (Goleman, 1998; Salovey \& Meyer, 1990) particularly the elements of emotional self-awareness and empathetic awareness of others' feelings, needs and desires. Mastenbroek (2000) argues that trust among organizational members also allows them to maintain a balanced expression of emotions, where strict control or suppression of one' anger is not mandatory. Tied to this trust and transcending the individual is the practice among colleagues of "honoring" emotions expressed in the workplace (Meyerson, 2000). When expressed emotions are acknowledged and respected, rather than suppressed and feared, the space within which organizational members are able to engage in emotional discourse expands--offering more opportunity for understanding of and support for necessary changes. Organizational settings and participants who foster and reflect a high level of comfort with anger expression, whose participants voluntarily manage this expression in consideration of others, help protect interpersonal relationships and increase the likelihood that anger expressions will remain within the space between thresholds. 
The Dual Threshold Model proposes that anger expressed in the space between thresholds is the most likely to produce positive consequences. Therefore, we propose the following hypothesis:

Hypothesis 2: When organizational members' anger expression remains in the space between the Expression and Impropriety Thresholds, positive outcomes increase.

\section{The Impropriety Threshold}

The Dual Threshold Model proposes that if expressed anger is considered inappropriate or unacceptable to organizational member observers, it has crossed the Impropriety Threshold, or “double crossed" (Callister \& Geddes, 2004). Anger expression characterized as aggressive, whether overt in the form of physical or verbal abuse, or expressed in a covert manner are obvious examples of expressed anger that have crossed the line of propriety (Geddes \& Baron, 1997; Morrill, 1989; Neuman \& Baron, 1998). Establishing and upholding "rules" of displaying and reacting to anger reflect formal and informal socialization processes that may be culturally, organizationally, or even industry based (Lord, Klimoski, \& Kanfer, 2002). Thus, verbal and nonverbal displays that break the rules, i.e., double cross, according to organizational observers, are more likely to have formal sanctions imposed by management, and informal sanctions by peers, in order to reinforce established cultural norms of propriety. Thus, we propose the following hypothesis.

Hypothesis 3: When organizational members' anger expression crosses the Impropriety

Threshold and is seen as going "over the line," negative outcomes increase.

In some cases when an organizational member has crossed the Impropriety Threshold, coworkers may make an effort to "retrieve" the individual who double-crossed (Callister and Geddes 2004). Thus, when colleagues help to bring the discussion and anger expression back 
into the space between thresholds, organizational outcomes may improve. In contrast, when colleagues fail to respond supportively to excessive emotional displays and distance themselves from the perpetrator or respond aggressively themselves, organizational members as a whole suffer with hindered opportunities for generating change. Therefore, the following hypotheses are proposed:

Hypothesis 4a: When organizational members respond supportively to individuals who cross the Impropriety Threshold, positive outcomes increase.

Hypothesis $4 b$ : When organizational members respond with sanctions toward individuals who cross the Impropriety Threshold, negative outcomes increase.

\section{METHOD}

\section{Pilot Study}

A preliminary survey was developed and distributed to 32 office workers of a mechanical services subsidiary of a large public utility. Thirteen full-time employees completed and returned the surveys for a response rate of $41 \%$. Respondents were ensured anonymity. The completed surveys were put in envelopes, sealed, and placed in a sealed collection box that researchers retrieved after two weeks.

The survey asked individuals to consider and describe 1) a specific instance in which they personally felt anger at work, and 2) a specific instance in which they personally witnessed an excessive display of anger at work. Survey respondents were also asked to provide their general attitudes toward anger and its expression in the organization. In addition, the survey assessed demographics and the respondents' affect towards their company. Five questions were openended in the pilot survey in order to generate a wide spectrum of responses and to help create categories of responses for use in the final survey. The five questions were: 
- Think of the last time some situation at work made you angry. With this situation in mind, describe what made you angry.

- What helps you express your anger about situations at work?

- What hinders you from expressing anger about situations at work?

- If you have personally witnessed someone who you felt went "too far" when expressing their work-related anger, what did they do that you felt was "over the top" regarding appropriateness?

- What happened to this individual after he or she went "too far": Formally by the company/management and informally by coworkers?

In addition, all questions with multiple choice options included an "Other" category that allowed us to expand response options as appropriate for the final survey. With data collected from the pilot survey, two raters working in tandem categorized participant responses. These categories were used as response sets in the final survey for all but the second question noted above, which proved confusing to respondents. This question was reworded for the final survey to read, "What makes you more likely to speak up at work when you're angry."

\section{Samples and Procedure}

Employees from a small aerospace and defense sub-contractor located in northeastern Pennsylvania were invited to participate in this study. Surveys were distributed to 59 full-time employees, 16 of whom returned completed questionnaires, representing a $27 \%$ response rate. We also distributed the survey to 38 upper class (junior or senior) undergraduate business majors at a small private college, and 81 upper class undergraduate business majors and 32 graduate business students at a large research university — all in the eastern United States. All students were employed at least part-time. Volunteers were given a token gift for participating. Students 
were instructed to return completed surveys in a sealed envelope to their instructors who passed the envelopes on to the researchers. Surveys completed at the organization were put in envelopes, sealed, and placed in a sealed collection box that researchers retrieved after two weeks.

Of the 180 participants in this study, $53 \%$ were female and $47 \%$ were male. The majority $(67 \%)$ of the respondents were between the ages of 21 and 30, 14\% were between 31 and 40 years old, $8 \%$ were over age $50,6 \%$ were 20 years old, and $5 \%$ were between the ages of 41 and 50. Most (78\%) participants were Caucasian. When asked about the highest level of education complete, $47 \%$ reported having some college, $28 \%$ had a college degree, $15 \%$ were in graduate school, and $9 \%$ had at most, a high school diploma. Five percent of the respondents were unionized. The average earnings for the group were slightly over $\$ 30,000$ per year. With respect to their jobs, $54 \%$ of the respondents worked full-time and $46 \%$ worked part-time. Thirty-three percent of the participants held their current job for more than one year but less than three years, $28 \%$ were in their job less than one year, $21 \%$ between three and five years, and $18 \%$ held their job for more than five years.

\section{Measures}

Survey topics examined anger at work in three categories: general attitudes toward anger, a specific occurrence of individually felt anger, and witnessing an excessive display of anger. Topics covering general attitudes towards anger included the types of situations that might make someone angry at work, and what might assist or hinder an individual in expressing that anger. Personal Anger Incident

Using a critical incident technique, respondents were asked to recall the most recent situation at work that made them angry. This technique is shown to be effective when eliciting 
information that may be considered sensitive (Dickson, Rainey, \& Hargie, 2003), and when the respondents are more highly involved in the situation (Burns, Williams, \& Maxham, 2000), both of which are conditions that may pertain to incidents of personal anger. With this angerprovoking situation in mind, respondents replied to questions about the incident.

\section{Independent and Dependent Variables}

Silent or Vocal Response. Individuals were asked to select all their responses to the situation at work that made them angry, including the following: "I communicated with the person involved;" "I communicated with management;" "I communicated with a coworker unrelated to the situation;" "I communicated with someone outside of work;" "I didn't communicate my anger to anyone, I kept it to myself;" and "Other (please specify)." These options were used to create our independent variable, silent or vocal response. Silent or vocal response was recoded as a dichotomous variable that had a value of one if respondents were organizationally silent (i.e. didn't communicate with anyone, communicated with an unrelated coworker, or with someone outside of work) and a value of zero if the individuals crossed the Expression Threshold by speaking to either the party involved or management.

Outcome to the Situation. The eventual outcome regarding the anger-provoking situation, which served as our dependent variable, was assessed with a single item that had three possible options: 1 = "It got worse," 2 = "It stayed the same," 3 = "It improved." Excessive Anger Displays

The questions involving excessive displays of anger were framed from an observer's perspective to reduce potential social desirability bias. Respondents were asked if they ever witnessed anyone crossing the Impropriety Threshold, i.e., going "too far" in their expression of anger, and if so, to answer questions about the incident and related outcomes. 


\section{Independent and Dependent Variables}

Excessive Anger Display. The nature of the witnessed excessive anger expression was explored by asking how the individual expressed his/her anger. This was used as the independent variable in our analyses of Hypotheses 3. Respondents were asked to select all that applied. Three types of behaviors were identified from the pilot study: "Inappropriate communication (i.e., demeaning comments, notes or emails);" "Verbal aggression (i.e., yelling, screaming, swearing);" and "Physical aggression (i.e., striking, pushing, throwing objects, etc.)." Each of these behaviors was coded with a dummy variable $(1=$ the behavior was observed; $0=$ the behavior was not observed). An "Other (please specify)" category was also included. Of the 167 surveys that asked the question in this form, 3 people provided descriptions in the "Other" option. One individual observed someone push/throw his tool box into objects, a second reported sabotage, and the third witnessed someone slandering a coworker. The first two responses were recoded into the physical aggression category, and the third into inappropriate communication.

Individual Outcomes. The formal and informal responses to the individual who crossed the Impropriety Threshold were examined and used in our analyses for Hypotheses 3 and 4. Respondents were asked to select all responses that applied. Formal responses included those that may be imposed only by management, including "Warning," "Probation," "Dismissal," and "Other (please specify)" as well as additional, relevant responses: "Incident not reported," "No formal sanctioning occurred," and "I don't know." Warning, probation, suspended and "Other" responses were combined to create a new variable, non-dismissal sanctions. Dismissal was used as a separate formal response. Informal responses included those imposed by coworkers, including "Coworkers distanced themselves from the offender," "Someone talked to the offender 
about his/her behavior," "Other (please specify)," "No informal sanctioning occurred," and "I don't know." Affirmative responses to "someone talked to the offender about his/her behavior" were recoded as a supportive response. Sanctioning responses included "coworkers distanced themselves from the offender" and the "Other" response in which a respondent noted a coworker physically threatened the offender. Category frequencies were used in the correlation tables (see Table 2).

Outcome to the Situation. The eventual outcome of the situation that prompted the excessive behavior was assessed with a single item: 1 = "It got worse," 2 = "It stayed the same," $3=$ "It improved."

\section{Related Variables}

To help answer research questions and enhance discussion of the findings, we also collected data on the following variables: Recency of the Personal Anger Incident; Causes of Anger; Help in Expressing Anger; Hindrances to Expressing Anger; and Affect toward the Organization.

Respondents also provided demographic information, including gender, race, age, marital status, income, education, union membership, full or part-time status, company and position tenure. Sex, age, education, organizational affect and race $($ dummy coded $1=$ white, $0=$ nonwhite) were used as controls in the regression analyses. In the case of the personal anger incident, time since the incident was also used as a control.

\section{Preliminary Analysis}

Using ANOVAs with a Tukey post hoc analysis, each anger item used in our empirical tests was compared for similarity across the five samples in our study. Of 21 possible ANOVAs, there were no significant differences between the samples for 18 of them. Thus, despite 
occupational and demographic differences in the five samples, the participant's responses to the anger questions were highly similar across the groups, helping justify the aggregation of groups into a final sample of 180 individuals.

\section{RESULTS}

Tables 1 and 2 contain the descriptive statistics and correlations for the variables of interest in the personal anger incident and excessive anger display analyses, respectively. Twenty-two percent of the respondents indicated that their personal anger incident occurred within the day or two prior to completing the survey, 19\% said it occurred sometime during the previous week, $28 \%$ reported the incident occurred more than a week but less than a month ago, and $25 \%$ said the incident happened within the past 6 months.

\section{Insert Tables $1 \& 2$ about here}

Hypotheses 1 and 2 predicted that the decision to remain silent or to cross the threshold of anger expression would be associated with negative and positive outcomes, respectively. These hypotheses were tested with a hierarchical regression analysis. The dependent variable was the outcome of the anger-producing situation. The first step in the regression included the controls: sex, age, race, education, organizational affect, and time since incident. In step two, the independent variable, silent or vocal response, was entered.

The standardized betas, $\mathrm{R}^{2}$ statistics, and overall $F$-statistic for the regression are contained in Table 3. The overall model was significant $\left(\mathrm{F}_{(7,157)}=4.90, \mathrm{p}<.001\right)$, and the variables in the model explained $18 \%$ of the variance in the outcome of the anger provoking situation. The first hypothesis predicted that people who fail to cross the Expression Threshold will have more negative outcomes, and the second hypothesis predicted that people who do cross the Expression Threshold will have more positive outcomes. The significant negative coefficient 
$(\beta=-.26, p<.001)$ on the independent variable, silent or vocal response, supports both hypotheses.

Insert Table 3 about here

Related to these hypotheses were two research questions exploring various factors that made an individual more and less likely to speak up at work when angry. Of the 180 respondents, 178 answered the question regarding hindrances to expressing anger. Since respondents were asked to select all that apply, the percentages do not total $100 \%$. The most common response was professionalism (43\%), followed by fear of management repercussions $(38 \%)$, and respect for others (31\%). Also cited were impression management concerns regarding how others would view them $(26 \%)$, e.g., one employee said that she didn't want "to seem like a whiner." The relative supportiveness of the organizational environment or climate was noted in $19 \%$ of the cases with remarks such as "lack of caring management," "lack of support of others," and "it's a waste of breath, nothing changes." Fifteen percent of the respondents indicated that fear of coworker repercussions was a reason to remain silent, e.g., "I always keep in mind that I have to work with these guys for years to come." Finally, 11\% of the respondents indicated that nothing hindered them from expressing their anger at work.

The second research question asked individuals to identify factors that made them more likely to cross the Expression Threshold, i.e., speak up when angry at work. Some of the items provided would typically be characterized as antecedents to anger, e.g., "injustice." Thus, it appears that sometimes the nature of the offense itself, rather than individual or organizational characteristics, may prompt organizational members to vocalize, rather than silence their anger.

Of the 180 participants, $101(56 \%)$ responded to this question, producing a broad range of responses. A factor most often reported (34\%) that increased the likelihood of individuals 
expressing anger was when they were personally impacted by the initial incident. A female real estate consultant said she would speak if the situation "causes any kind of personal harm," and a manager in the healthcare industry said she would be more likely to cross the Expression Threshold, "when something is specifically directed at me related to my professionalism and work ethics." The second most common factors facilitating anger expression (18\% each) were perceived injustice and escalation or intensity of the problem, followed by concern for another's well-being (9\%), and the inadequate performance of others (9\%). More factors prompting the vocalization of anger in the workplace included a belief in the effectiveness of speaking up (7\%), the relative importance or seriousness of the situation (7\%), and having a supportive environment (7\%). Other situations noted by survey respondents included inefficiencies (6\%), reduced fear of reprisals (3\%), the status of the person causing the problem (2\%), time of day (2\%), illegitimate activities (2\%), expressing anger only when asked for input (2\%), and feeling like there are no other options (1\%). A few respondents (4\%) said nothing prevents them from speaking up at work when angry and $2 \%$ indicated they wouldn't speak up at all when angry.

The third hypothesis deals with witnessed excessive anger expression, in which an organizational member is observed crossing the Impropriety Threshold. Hypotheses 3 specifically predicted that negative results increase when this second threshold is crossed. One hundred fifty-five respondents or $86 \%$ of the people who completed this survey reported personally witnessing someone at work expressing their work-related anger in a manner they deemed as "crossing the line." Respondents were asked to select all types of behaviors witnessed that they considered excessive. They reported occurrences of inappropriate communication in $42 \%$ of the observed incidents, verbal aggression in $75 \%$ and physical aggression in $23 \%$ of the cases of expressed anger. 
In approximately $41 \%$ of these excessive anger displays, respondents were aware of some type of formal sanction or response by management; in $31 \%$ of the occurrences, respondents believed no formal sanctions occurred, and $12 \%$ of the time, respondents noted the incident went unreported. Of those formally sanctioned, warnings $(60 \%)$ were used the most often, probation occurred $5 \%$ of the time, suspensions were imposed $3 \%$ of the time. Thirty-one percent of the employees formally sanctioned were dismissed. Informally, coworkers responded to excessive anger in approximately $55 \%$ of the incidents; $26 \%$ of the time, no response to the excessive anger occurred informally, and in $18 \%$ of the instances, the witness was unaware of what happened to the individual informally. Sixty-one percent of the informal responses had some form of sanctioning (i.e., distanced themselves or responded aggressively to the offender) while $52 \%$ responses were supportive, in that someone talked with the offender

Given that all cases examined involved some form of excessive anger expression, we pursued Hypothesis 3 by examining correlations between these variables and related organizational outcomes and individual responses to these displays. Table 2 lists the three categories of previously-identified, excessive anger displays - inappropriate communication, verbal aggression, and physical aggression - as well as formal and informal responses/sanctions to the excessive anger display, and the overall outcome to the situation. We found partial support for this hypothesis. The three categories of excessive anger displays were negatively related to the overall outcome variable, though not significantly. However, the correlation between physical aggression and the situational outcome $(\mathrm{r}=-.153, \mathrm{p}=.064)$ was large enough to suggest that crossing the Impropriety Threshold in this manner may lead to the underlying situation getting worse. We also found that individuals who engaged in physical aggression were more likely to be formally reported $(r=-.16, p<.05)$ and dismissed $(r=.20, p<.05)$. 
However, those engaging in inappropriate communication were unlikely to be dismissed ( $\mathrm{r}=-$ $.17, \mathrm{p}<.05)$, and those engaging in verbal aggression were likely to have nothing occur formally $(\mathrm{r}=.17, \mathrm{p}<.05)$, which suggests a hierarchy of egregiousness regarding anger expression that crosses the Impropriety Threshold. We found further a significant, negative correlation between the situation outcome (indicating the situation got worse) and dismissal of the offender $(\mathrm{r}=-.26$, $\mathrm{p}<.01$ ), implying that certain organizational responses/sanctions, rather than excessive anger displays themselves, may make the initially problematic situation worse.

Hypotheses $4 \mathrm{a}$ and $4 \mathrm{~b}$ examined the impact of informal behaviors on the outcome of an excessive anger incident. These hypotheses were tested with a hierarchical regression analysis. The dependent variable was the outcome of the anger-producing situation. The first step in the regression included the controls: sex, age, race, education, and organizational affect. The second step contained the formal responses to the excessive anger incident: incident not reported, nothing was done, non-dismissal sanctions (warning, probation, suspended), and employee dismissal. In step three, the key independent variables - informal responses - were entered: nothing was done, sanctioning (distancing selves from offender or responding aggressively), and supportive behaviors (talking to the angry employee).

The standardized betas, $\mathrm{R}^{2}$ statistics, and overall $F$-statistic for this regression are contained in Table 4. The overall model was significant $\left(\mathrm{F}_{(12,119)}=3.198, \mathrm{p}<.001\right)$, and the variables in the model explained $24 \%$ of the variance in the outcome of the excessive anger incident. Of the variance explained, over half (14\%) was attributable to the informal responses of coworkers and peers after factoring in both the observer's demographics and formal action by management. Hypothesis 4a's prediction that positive outcomes increase when organizational members respond supportively to individuals who cross the Impropriety Threshold, was not 
supported, although the relevant coefficient was in the expected direction. H4b predicted that when organizational members respond with sanctions, negative outcomes will increase. This hypothesis was supported by the significant negative coefficient $(\beta=-.28, \mathrm{p}<.01)$ for sanctioning behavior.

\section{Insert Table 4 about here}

\section{DISCUSSION}

This study was a first attempt to empirically test the Dual Threshold Model of anger expression (Callister \& Geddes, 2004). Data included reasons for crossing or not crossing the Expression Threshold and outcomes following anger expression, including the improvement (or not) of the initially problematic situation, and formal versus informal sanctions imposed by organizational members following excessive anger displays. Hypotheses pursued corresponded with key propositions of the Dual Threshold model, namely that not crossing and double crossing thresholds leads to more negative consequences, and staying in the space between thresholds leads to more positive consequences. Our results support these propositions, with some noted exceptions regarding the consequences of crossing the Impropriety Threshold.

The hypothesis that the suppression of anger leads to negative outcomes was supported. Individuals who did not cross the first threshold and remained organizationally silent saw the anger-provoking situation worsen. This silence included situations in which individuals expressed anger to uninvolved coworkers, rather than approach those responsible or able to make a difference. In contrast, organization members who chose to express their anger to those directly involved or in a position to respond with authority, saw the overall situation at work improve. These findings provide significant support for the Dual Threshold Model 
When crossing the Impropriety Threshold, people can expect a variety of sanctions, both formal and informal, which lead to more unfavorable consequences for the individuals expressing their anger; however, it is less clear if expressing excessive anger always produces negative organizational results. Witnesses were aware of formal sanctions (warning, probation, suspension, dismissal) in just under half of the cases, and were aware of informal sanctions (distancing from the offender, responding aggressively) in just over half of the cases. Nevertheless, no association was found between the outcome of the situation and all three types of excessive anger.

The situation worsened, however, if the employee expressing excessive anger was dismissed, suggesting that the sanctions themselves may have an impact on the underlying problem. Correlations showed management "doing nothing formally" positively related to coworkers "doing nothing informally" $(\mathrm{r}=.17, \mathrm{p}<.05)$, which in turn was associated with the initially problematic situation improving $(\mathrm{r}=.26, \mathrm{p}<.01)$. However, when coworkers informally sanctioned the offender, i.e., distanced themselves or responded aggressively, the situation deteriorated. This suggests that even in situations of excessive anger displays by employees, if organizational members can withhold sanctions, the space between thresholds widens and the possibility of anger expressions and discussions moving back into the space between thresholds increases - which lead to more positive individual and organizational outcomes, according to the Dual Threshold Model.

\section{Limitations and Future Research}

There are limitations to this study that merit acknowledgement, including the oft admitted concerns with cross-sectional and self-report data, as well as use of student participants. Nevertheless, given the sensitive nature of the phenomenon of interest, the fact that all students 
were currently employed in multiple organizations and industries, and the few significant differences observed between student and non-student respondents, we felt this methodology would be more ethical than experiments and more valid than responses to role plays or case analyses. Further, use of data provided by working students, representing a range of ages, hierarchical status, and work experience, likely increased the number and variety of anger incidents considered. A related limitation pertains to the use of third party observation in the excessive anger display data collection. There is an inherent weakness to this technique as witnesses may not be familiar with or aware of all causes of an incident, the sanctions imposed, or exact outcomes regarding the underlying situation that prompted the behavior. Nevertheless, given that perception of impropriety is an observer-based phenomenon (Callister \& Geddes, 2004) and the possibility of social desirability biases, witnessed excessive anger incidents were deemed preferable over asking individuals to report incidents when they had personally gone "over the top" expressing anger.

Other potential limitations of the study have to do with the nature of the questions and response sets used in the survey. Specifically, in contrast to the personal anger incident, we did not ask how recently the excessive anger event occurred. Although it is likely that excessive anger incidents are relatively intense, unique, and thus, memorable, for events that have occurred recently, i.e., within the past few days or weeks, the organization simply may not have had time to respond to the situation or the "offending" employee. This would, therefore, increase survey respondents reporting that "nothing happened" or that the situation "did not improve," when, if more time had passed, both might have occurred. Thus, there may be an advantage in future research to ask individuals to recall incidents that have occurred within the last few months, but not within the past few days or weeks. Regarding response sets, our survey provided options for 
anger antecedents such as "inadequate performance of coworker or manager," but failed to include other possible stakeholders, such as clients, customers or vendors, whose behavior may also provoke an anger incident at work. This limitation was somewhat minimized by our use of the "Other (Please Specify)" option, to which a number of respondents replied. Further, the response set for formal actions taken by the organization provided no option for a nonsanctioning managerial response, such as talking to the offender. A similar limitation is found with the response set for informal actions, in that there was no option for aggressive retaliation by co-workers. Again, both limitations were somewhat minimized in this study through the option to write in an "Other" response, which many did. Further, although we coded "talking to offender" as a supportive response to the individual who expressed anger excessively, future research might want to more clearly describe this type of interaction to respondents as an effort to try to help or be supportive of the individual.

In anger-eliciting situations, Fitness (2000) found differences in immediate and subsequent behavior between individuals based on their status relative to the offender's status, and Mastenbroek (2000) suggests that patterns of emotion management are related to patterns of dependency. We did not include employee status for either the personal anger incident or the witnessed excessive incident; nevertheless, future research should consider the likelihood, type, and consequence of anger expression in the context of hierarchical and peer relationships. Still unanswered are questions such as: Is anger expressed upward more personally problematic and anger expressed downward more organizationally damaging? Does informality among peers (more typical than informality between boss and employee) lead to more accepting and acceptable displays of anger? How does status reduce the fear of formal sanctions when expressing anger? 
What might also benefit from future research is further exploration into the concept of organizational silence. This phenomenon was operationalized using Callister and Geddes' (2004) definition, i.e., choosing not to speak at all or speaking to someone who cannot affect the situation. However, respondents to our survey indicated that there may be situations when coworkers voice anger on behalf of their colleagues. For instance, one full-time worker specifically said she would be willing to express anger for a coworker who doesn't speak up. Thus, future research should examine the prevalence and impact of "surrogates" who speak for colleagues uncomfortable expressing their own anger.

Anger, like all emotions, is the joint product of social interactions and personal characteristics. One feels provoked during social exchange in a way that increases "vulnerability to feeling demeaned or belittled" (Lazarus \& Cohen-Charash, 2001, p. 62). Although beyond the scope of our preliminary research, individual trait and personality differences on one's propensity to cross emotion thresholds seem an appropriate focus for future research. Tendencies toward emotional contagion and burnout might also prove useful in understanding the social consequences of anger expression — both for the individual expressing anger and those witnessing and interacting with angry employees. For instance, Bartel and Saavedra, (2000) show that work groups are predisposed to experience unpleasant moods collectively and Sullins' (1991) research suggests that negative emotions transfer between people more readily than positive ones. Thus, due to the increased possibility of negative emotional contagion, excessive anger displays may contribute to more negative emotions among coworkers and further exacerbate the underlying situation, especially when responded to with sanctioning and aggressive responses by coworkers. In contrast, if employees trust that their coworkers will be supportive of honestly-expressed emotion (however intense or negative), this might enhance 
favorable outcomes from anger displays. Future research should consider the role trust plays in creating supportive (versus defensive) organizational climates that allow more latitude in emotion displays, i.e., more space between expression thresholds.

The implications for management and scholars alike are significant. Organizations and its members can no longer be viewed or studied as purely rational, reasoning, unemotional entities. Our research provides empirical support for the Dual Threshold Model suggesting it is a viable and useful framework from which to examine emotional exchanges and their consequences in the organization. Further, its key propositions, which assert positive consequences from anger expression suggest the need for training not only individual emotion management, but also supportive organizational responses. Expressed anger, even at times excessive, if not immediately sanctioned by management and coworkers, may "bring an outpouring of fresh ideas from all levels of an organization" (Perlow \& Williams, 2003, p. 58) and be an effective instrument for positive organizational change. 


\section{REFERENCES}

Andersson, L. M. (1996). Employee cynicism: An examination using a contract violation framework. Human Relations, 49, 1395-1418.

Andersson, L. M. (1999). Tit for tat? The spiraling effect of incivility in the workplace. Academy of Management Review, 24(3), 452-471.

Barsade, S. G. (2002). The Ripple Effect: Emotional Contagion and Its Influence on Group Behavior. Administrative Science Quarterly, 47, 644-675.

Bartel, C. A., \& Saavedra, R. (2000). The collective construction of work group moods. Administrative Science Quarterly, 45, 197-231.

Burns, A. C., Williams, L. A., \& Maxham, J. T., III. (2000). Narrative text biases attending the critical incidents technique. Qualitative Market Research: An International Journal, 3, 178-186.

Callister, R. R., \& Geddes, D. (2004). Crossing the line: A dual threshold model of expressing anger in organizations. Paper presented at the annual meeting of the International Association of Conflict Management, Pittsburgh.

Callister, R. R., Gray, B., Schweitzer, M., Gibson, D., \& Tan, J. S. (2003, August). Organizational contexts and outcomes of anger expressions in the workplace. Paper presented at the annual meeting of the Academy of Management, Seattle.

Dickson, D. A., Rainey, S., \& Hargie, O. D. W. (2003). Communicating sensitive business issues: Part 2. Corporate Communications: An International Journal, 8, 121-127.

Fineman, S. (1993). Emotion in organizations. Newbury Park, CA: Sage.

Fineman, S. (2000). Emotion in organizations (2nd Ed). Thousand Oaks, CA: Sage.

Fineman, S. (2003). Understanding emotion at work. Thousand Oaks, CA: Sage Publications.

Fitness, J. (2000). Anger in the workplace: An emotion script approach to anger episodes between workers and their. Journal of Organizational Behavior, 21, 147-162.

Geddes, D. \& Baron, R.A. (1997). Workplace aggression as a consequence of negative performance feedback. Management Communication Quarterly, 10, 433-454.

Goleman, D. (1998). Working with emotional intelligence. New York: Bantam Books.

Gundlach, M. J., Douglas, S. C., \& Martinko, M. J. (2003). The decision to blow the whistle: A social information processing framework. Academy of Management Review, 28, 107-123. 
Kelly, J. R., \& Barsade, S. G. (2001). Mood and Emotions in Small Groups and Work Teams. Organizational Behavior and Human Decision Processes, 86, 99-130.

Lazarus, R. S. (1999). Stress and emotion. New York, NY: Springer.

Lazarus, R. S., \& Cohen-Charash, Y. (2001). Discrete emotions in organizational life. In R. Payne \& C. Cooper (Eds.), Emotions at work (pp. 47-81). New York: John Wiley \& Sons, Ltd.

Lord, R. G., Klimoski, R. J., \& Kanfer, R. (2002). Emotions in the workplace: Understanding the structure and role of emotions in organizational behavior. San Francisco, CA: JosseyBass.

Martin, J., Knopoff, K. \& Beckman, C. (1998). An alternative to bureaucratic impersonality and emotional labor: Bounded emotionality at The Body Shop. Administrative Science Quarterly, 43, 429-469.

Mastenbroek, W. (2000). Organizational behavior as emotion management. In N. M. Ashkanasy, C. E. J. Hartel \& W. J. Zerbe (Eds.), Emotions in the workplace: Research, theory and practice (pp. 19-35). Westport, Connecticut: Quorum Books.

Meyerson, D. E. (1998). Feeling stressed and burned out: A feminist reading and re-visioning of stress-based emotions within medicine and organization science. Organization Science, 9, 103-118.

Meyerson, D. E. (2000). If emotions were honoured: A cultural analysis. In S. Fineman (Ed.), Emotion in organizations (2nd ed., pp. 167-183). Thousand Oaks, CA: Sage Publications.

Morrill, C. (1989). The Management of Managers: Disputing in an Executive Hierarchy. Sociological Forum, 4(3), 387-408.

Morris, J. A., \& Feldman, D. C. (1996). The dimensions, antecedents, and consequences of emotional labor. Academy of Management Journal, 21, 986-1010.

Morrison, E. W., \& Milliken, F. J. (2000). Organizational silence: A barrier to change and development in a pluralistic world. Academy of Management Review, 25, 706-725.

Neuman, J. H., \& Baron, R. A. (1998). Workplace violence and workplace aggression: Evidence concerning specific forms, potential causes, and preferred targets. Journal of Management, 24, 391-419.

Perlow, L., \& Williams, S. (2003). Is silence killing your company? Harvard Business Review, $81,52-58$. 
Putnam, L. L., \& Mumby, D. (1993). Organizations, emotion and the myth of rationality. In S. Fineman (Ed.), Emotion in organizations, (pp. 36-57). Newbury Park, CA: Sage.

Rafaeli, A., \& Worline, M. (2001). Individual emotion in work organizations. Social Science Information, 40, 95-123.

Salovey, P., \& Meyer, J. D. (1990). Emotional intelligence. Imagination, Cognition and Personality, 9, 185-211.

Shunk, G. S. (2003). Facing your anger. Training and Development,, 57 (10), 65.

Sullins, E. S. (1991). Emotional contagion revisited: Effects of social comparison and expressive style on mood convergence. Personality \& Social Psychology Bulletin, 17, 166-174.

Waldron, V., R., \& Krone, K. J. (1991). The experience and expression of emotion in the workplace. Management Communication Quarterly, 4, 287-309. 
Table 1

Personal Anger Incident Data Means, Standard Deviations, and Correlations

\begin{tabular}{|c|c|c|c|c|c|c|c|c|c|c|}
\hline & Mean & $\mathrm{SD}$ & $\mathrm{N}$ & 1 & 2 & 3 & 4 & 5 & 6 & 7 \\
\hline \multicolumn{11}{|l|}{ Last time angry at work: } \\
\hline 1 Time since anger occurrence & 2.751 & 1.232 & 177 & & & & & & & \\
\hline 2 Silent or Vocal Response & .542 & .500 & 177 & .017 & & & & & & \\
\hline 3 Outcome of situation & 2.377 & .563 & 175 & $.250 * * *$ & $*-.254 * * *$ & & & & & \\
\hline 4 Affect towards organization & 4.000 & 1.047 & 178 & $.231 * *$ & -.077 & $.258 * * *$ & & & & \\
\hline $5 \mathrm{Sex}$ & .468 & .500 & 173 & -.084 & -.079 & .011 & .049 & & & \\
\hline 6 Age & 2.406 & .977 & 175 & -.003 & .011 & .019 & .049 & -.071 & & \\
\hline 7 Race & .776 & .418 & 174 & -.120 & .091 & .006 & .076 & .135 & .082 & \\
\hline 8 Education & 3.551 & .937 & 176 & .004 & .074 & -.015 & .062 & -.113 & -.092 & -.060 \\
\hline
\end{tabular}

$* \mathrm{p}<.05 . * * \mathrm{p}<.01 . * * * \mathrm{p}<.001$ 
Table 2

Witnessed Display of Excessive Anger Data Means, Standard Deviations, and Correlations

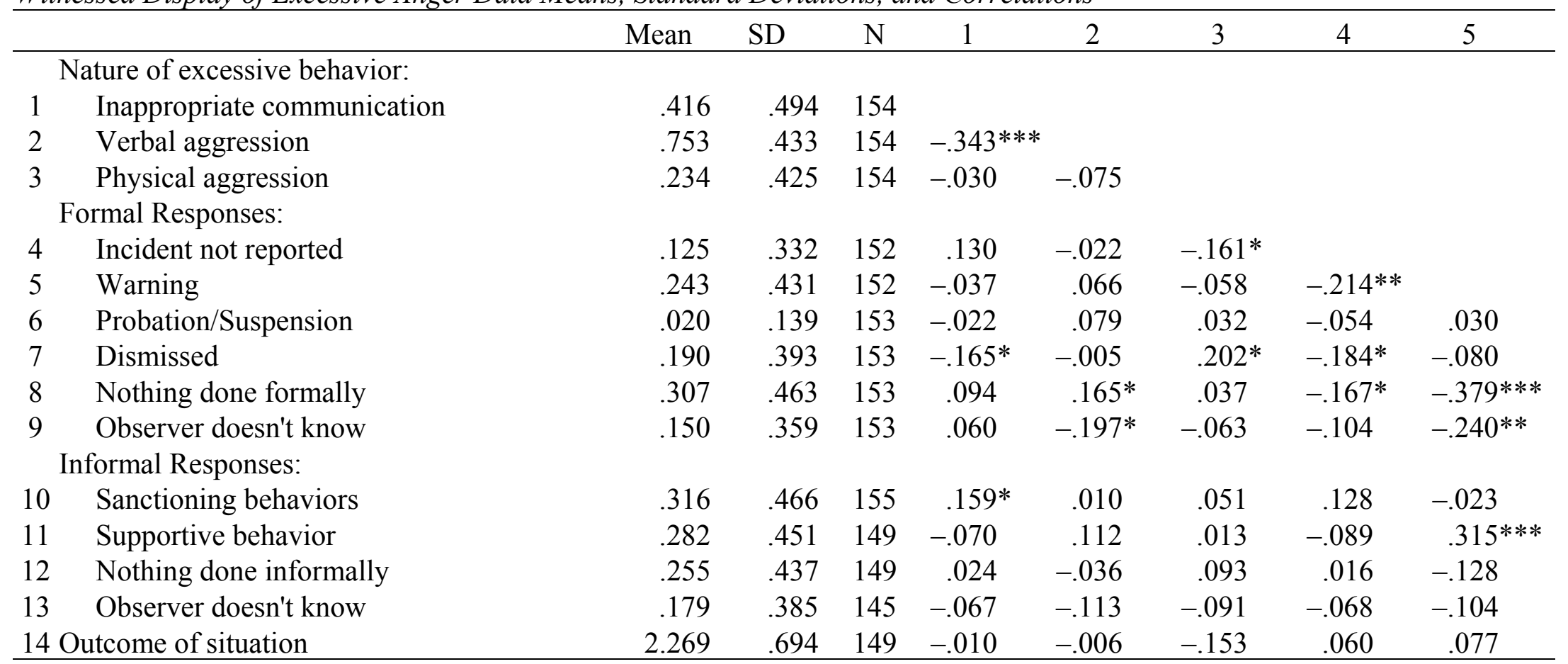

$* \mathrm{p}<.05 . * * \mathrm{p}<.01 . * * * \mathrm{p}<.001$. 
Table 2 (continued)

Witnessed Display of Excessive Anger Data Means, Standard Deviations, and Correlations

\begin{tabular}{|c|c|c|c|c|c|c|c|}
\hline 6 & 7 & 8 & 9 & 10 & 11 & 12 & 13 \\
\hline 1 & & & & & & & \\
\hline 2 & & & & & & & \\
\hline 3 & & & & & & & \\
\hline 4 & & & & & & & \\
\hline 5 & & & & & & & \\
\hline 6 & & & & & & & \\
\hline $\begin{array}{ll}7 & .052\end{array}$ & & & & & & & \\
\hline $8-.094$ & $-.322 * * *$ & & & & & & \\
\hline $9-.059$ & $-.203^{*}$ & $-.240 * *$ & & & & & \\
\hline 10.105 & -.010 & .029 & -.132 & & & & \\
\hline $11.232 * *$ & -.058 & -.155 & -.099 & $-.216 * *$ & & & \\
\hline $12-.085$ & -.037 & $.173 *$ & -.039 & $-.377 * * *$ & $-.367 * * *$ & & \\
\hline $13-.068$ & .120 & -.080 & $.289 * * *$ & $.334 * * *$ & $-.293 * * *$ & $-.180 *$ & \\
\hline $14-.125$ & $-.58 * *$ & -.020 & .142 & $-.347 * * *$ & .099 & $.255^{* *}$ & -.043 \\
\hline
\end{tabular}


Table 3.

Standardized Regression Coefficients Predicting Outcome

Following Personal Anger Expression

\begin{tabular}{llc}
\hline Step & & Final $\beta$ \\
\hline 1 & Sex & -.000 \\
& Age & .007 \\
& Race & .043 \\
& Education & -.002 \\
& Affect towards organization & $.183^{*}$ \\
& Time since anger incident & $.224^{* *}$ \\
2 & Silent or Vocal Response & $-.264^{* * *}$ \\
& & \\
& Change in $\mathrm{R}^{2}$ at Step 1 & $.113^{* *}$ \\
& Change in $\mathrm{R}^{2}$ at Step 2 & $.067^{* * *}$ \\
& Overall Model F & $4.90^{* *}$ \\
& Overall $\mathrm{R}^{2}$ & .179 \\
\hline
\end{tabular}

$* \mathrm{p}<.05 . * * \mathrm{p}<.01 . * * * \mathrm{p}<.001$.

Note. Negative sign means variable contributed to situation getting worse. 
Table 4

Standardized Regression Coefficients Predicting Outcome

Following Excessive Anger Display

\begin{tabular}{|c|c|c|}
\hline \multicolumn{2}{|c|}{ Step } & Final $\beta$ \\
\hline \multirow[t]{5}{*}{1} & Sex & .041 \\
\hline & Age & -.099 \\
\hline & Race & .018 \\
\hline & Education & -.050 \\
\hline & Affect towards organization & .050 \\
\hline \multirow[t]{5}{*}{2} & Formal Response: & \\
\hline & Incident not reported & .043 \\
\hline & Nothing done & -.101 \\
\hline & Non-dismissal sanctions & -.004 \\
\hline & Dismissal & $-.277 *$ \\
\hline \multirow[t]{9}{*}{3} & Informal Response: & \\
\hline & Nothing done & .166 \\
\hline & Sanctioning behavior & $-.280 * *$ \\
\hline & Supportive behavior & .087 \\
\hline & Change in $\mathrm{R}^{2}$ at Step 1 & .016 \\
\hline & Change in $\mathrm{R}^{2}$ at Step 2 & $.086^{*}$ \\
\hline & Change in $\mathrm{R}^{2}$ at Step 3 & $.142 * * *$ \\
\hline & Overall Model F & $3.20 * * *$ \\
\hline & Overall $\mathrm{R}^{2}$ & .244 \\
\hline
\end{tabular}

$* \mathrm{p}<.05$. ** $\mathrm{p}<.01 . * * * \mathrm{p}<.001$.

Note. Negative sign means variable contributed to situation getting worse. 


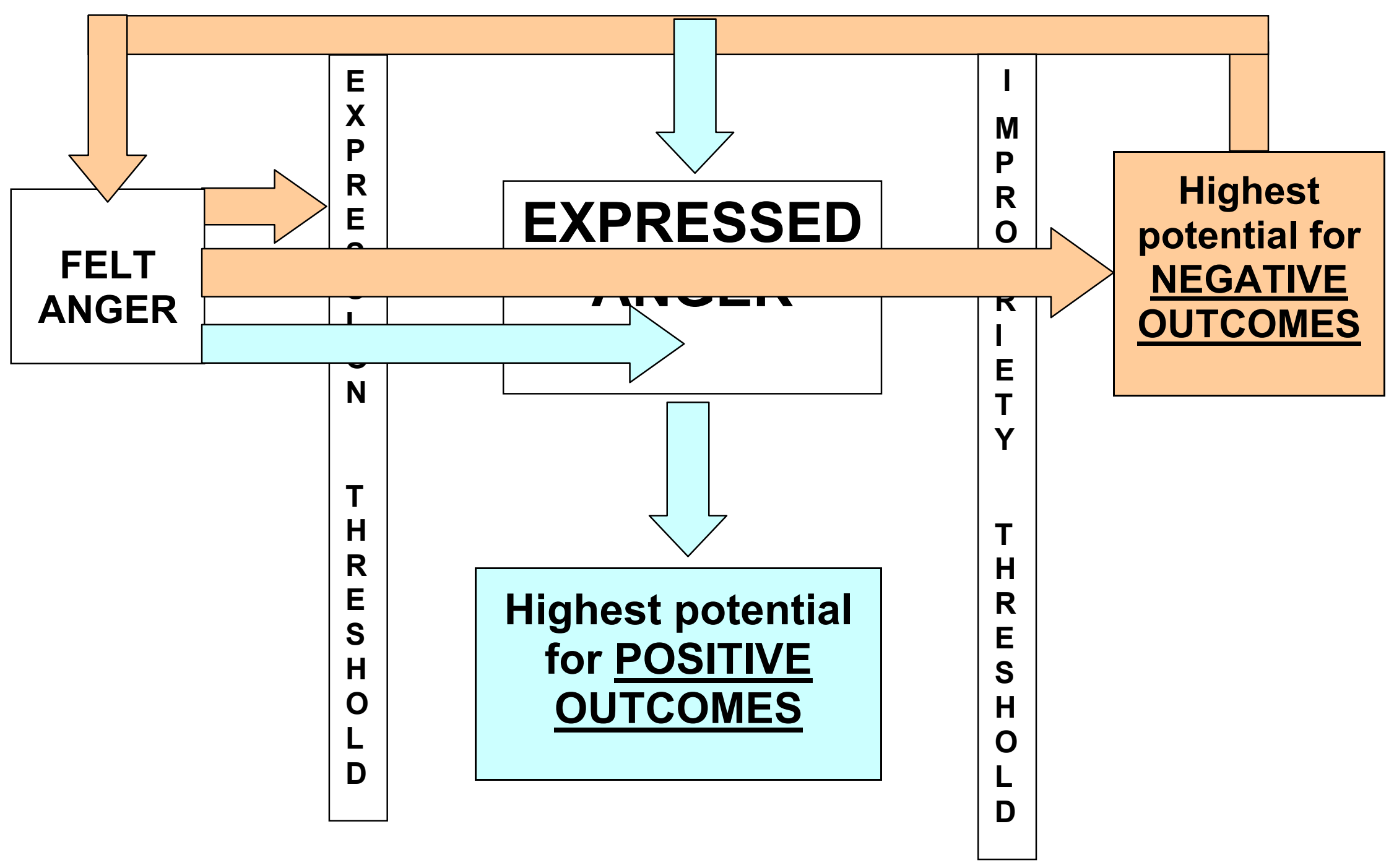

Figure 1. The Dual Threshold Model of Expressing Anger in the Workplace

Reprinted with permission from Callister, R. R., \& Geddes, D. (2004). Crossing the line: A dual threshold model of expressing anger in organizations. Paper presented at the International Association of Conflict Management, Pittsburgh, PA 